\title{
Consórcios alface-cenoura e alface-rabanete sob manejo orgânico
}

\author{
Ailena Sudo Salgado(1), José Guilherme Marinho Guerra ${ }^{(2)}$, Dejair Lopes de Almeida ${ }^{(2)}$, \\ Raul de Lucena Duarte Ribeiro( ${ }^{(3)}$, José Antonio Azevedo Espindola ${ }^{(2)}$ e José Aparício de Aquino Salgado(4)
}

\begin{abstract}
(1) Ministério da Agricultura, Pecuária e Abastecimento, Superintendência Federal de Agricultura no Estado do Rio de Janeiro, Av. Rodrigues Alves, no 129, sala 601, CEP 20081-250 Rio de Janeiro, RJ. E-mail: ailena@agricultura.gov.br (2)Embrapa Agrobiologia, BR 465, Km 7, CEP 23851-970 Seropédica, RJ. E-mail: gmguerra@cnpab.embrapa.br, dejair@cnpab.embrapa.br, jose@cnpab.embrapa.br (3)Universidade Federal Rural do Rio de Janeiro, BR 465, Km 7, CEP 23851-970 Seropédica, RJ. (4)Secretaria de Estado de Agricultura, Abastecimento, Pesca e Desenvolvimento do Interior do Estado do Rio de Janeiro, Alameda São Boaventura, no 770, CEP 24120-191 Niterói, RJ. E-mail: zeaparicio@hotmail.com
\end{abstract}

\begin{abstract}
Resumo - Dois experimentos foram conduzidos, por dois anos consecutivos, em Seropédica, RJ, com o objetivo de avaliar o desempenho agronômico dos consórcios das cultivares de alface 'Regina 71' (lisa) e 'Verônica' (crespa) com cenoura 'Brasília' e rabanete 'Híbrido no 19', sob manejo orgânico, assim como determinar as quantidades de macronutrientes exportadas. O delineamento experimental usado foi o de blocos ao acaso, com quatro repetições. No primeiro experimento, os tratamentos consistiram de alface crespa em consórcio com cenoura, alface crespa em consórcio com rabanete e os cultivos solteiros. No segundo experimento, usou-se alface lisa em lugar da crespa. Nos consórcios entre cenoura e alface crespa ou lisa, foram observados índices de uso eficiente da terra, superiores a 1,60. Nos consórcios de rabanete com alface, crespa ou lisa, esses índices foram de 1,54 e 1,27 , respectivamente. As quantidades de nutrientes extraídas do sistema pelos produtos colhidos foram inferiores aos aportes efetuados, evidenciando a viabilidade de qualquer dos consórcios avaliados.
\end{abstract}

Termos para indexação: cultivos consorciados, balanço de nutrientes, Daucus carota, Lactuca sativa, Raphanus sativus.

\section{Intercropping of lettuce-carrot and lettuce-radish under organic management}

\begin{abstract}
Two experiments were carried out, in two consecutive years, at Seropédica, RJ, Brazil, aiming to evaluate the agronomic performance of intercropping of lettuce cvs. Regina 71 (smooth leaf) and Verônica (crisp leaf) with carrot (cv. Brasília) and radish (cv. Hybrid number 19), under organic management. The amount of nutrients exported from the system by harvesting was also evaluated. The experimental design used was of completely randomized blocks, with four replications. In the first experiment, treatments consisted of lettuce with crisp leaves intercropped with carrot, lettuce with crisp leaves intercropped with radish and sole crops. In the second experiment, lettuce with smooth leaves was used instead of lettuce with crisp leaves. Intercropping of carrot and lettuce, with crisp or smooth leaf, presented land equivalent ratios higher than 1.60. Intercropping of radish and lettuce, with crisp or smooth leaf, presented land equivalent ratios of 1.54 and 1.27, respectively. Besides, the amounts of nutrients extracted by harvested products were lower than the inputs, pointing out the viability of the tested intercroppings.
\end{abstract}

Index terms: intercropping, nutrient balance, Daucus carota, Lactuca sativa, Raphanus sativus.

\section{Introdução}

Cultivos consorciados encontram-se bastante difundidos entre produtores rurais de regiões tropicais (Vandermeer, 1990), cujos fatores climáticos, como temperatura e radiação solar, não apresentam limitações. Entre as vantagens proporcionadas pelos consórcios em relação aos cultivos solteiros, podem ser destacadas: aproveitamento mais eficaz dos recursos naturais
(Humphries et al., 2004), favorecimento de populações de organismos benéficos no agroecossistema (Zhang et al., 2004), redução de insetos-praga (Hooks \& Johnson, 2003), e maior proteção contra a erosão (Iijima et al., 2004).

Algumas desvantagens podem ser associadas a culturas consorciadas, tais como aumento de mão-de-obra, tanto nos tratos culturais quanto na colheita, e competição entre as espécies (Fageria, 1989; Baumann et al., 2001). 
Apesar dos benefícios resultantes da realização de consórcios, há poucos estudos sobre sua utilização na agricultura orgânica em regiões de clima tropical. São necessários estudos que permitam melhor entendimento da contribuição dessa prática cultural aos sistemas orgânicos de produção, especialmente aqueles cultivados com hortaliças que se destacam no desempenho nutricional e mercadológico, como a alface, cenoura e rabanete.

Fatores como a identificação de cultivares e o ajuste de arranjos populacionais adequados podem ser manipulados para melhorar o uso dos recursos naturais e a eficiência do consórcio dessas hortaliças (Negreiros et al., 2002; Barros Júnior et al., 2005). Na avaliação de cultivares de alface em consórcio com cenoura e em cultivo solteiro, Caetano et al. (1999) verificaram comportamento diferenciado entre as cultivares nos sistemas estudados, com aumento de mais de $70 \%$ no uso da terra no sistema consorciado. De forma similar, Oliveira et al. (2005) constataram otimização do uso da terra de cerca de 59\% no consórcio entre rabanete e repolho, depois do pré-cultivo com a leguminosa Crotalaria juncea.

Entre os indicadores empregados para avaliar o desempenho agronômico de sistemas consorciados, podese destacar o índice de uso eficiente da terra (UET), que fornece uma medida das vantagens obtidas no rendimento de dois ou mais cultivos consorciados, quando comparado ao rendimento obtido com os respectivos cultivos solteiros (Gliessman, 2001). Este autor destaca que valores de UET superiores a 1,0 indicam que a produtividade das culturas no consórcio é maior que as obtidas nos respectivos cultivos solteiros, caracterizando interferências positivas entre as espécies consorciadas. De acordo com Altieri (2002), associações entre espécies, cujos sistemas radiculares são capazes de explorar camadas diferentes do solo, permitem a extração de nutrientes que não estariam disponíveis para uma das espécies em monocultura.

O objetivo deste trabalho foi avaliar o desempenho agronômico dos consórcios entre alface e cenoura e entre alface e rabanete, e determinar as quantidades de nutrientes exportadas do sistema, sob manejo orgânico, comparativamente aos cultivos solteiros das três hortaliças.

\section{Material e Métodos}

Os experimentos foram conduzidos, ao longo de 1996 e 1997, em área pertencente ao Sistema Integrado de Produção Agroecológica - SIPA (Fazendinha Agroecológica Km 47), projeto de cooperação técnica entre a Embrapa Agrobiologia e Embrapa Solos, a Empresa de Pesquisa Agropecuária do Estado do Rio de Janeiro (Pesagro-Rio/Estação Experimental de Seropédica) e a Universidade Federal Rural do Rio de Janeiro (Almeida et al., 2003). O SIPA localiza-se no Município de Seropédica, Região Metropolitana do Estado do Rio de Janeiro.

O clima da região pertence à classe Aw, segundo a classificação de Köppen. O solo é classificado como Argissolo Vermelho-Amarelo, cuja análise, de acordo com Embrapa (1997), apresentou os resultados na camada de 0-20 cm: C, 7,6 $\mathrm{g} \mathrm{kg}^{-1}$; $\mathrm{pH}$ em água, 4,6; Al, $1,0 \mathrm{mmol}_{\mathrm{C}} \mathrm{dm}^{-3}$; Ca, $21 \mathrm{mmol}_{\mathrm{C}} \mathrm{dm}^{-3} ; \mathrm{Mg}, 12 \mathrm{mmol}_{\mathrm{C}} \mathrm{dm}^{-3}$; P, $23 \mathrm{mg} \mathrm{dm}^{-3}$ e K, $109 \mathrm{mg} \mathrm{dm}^{-3}$.

A área encontrava-se previamente coberta com capim-cameroon (Pennisetum purpureum), incorporado durante o preparo do solo, que consistiu em aração, gradagem e destorroamento com enxada rotativa. Posteriormente, os canteiros foram levantados com auxílio de microtrator.

Os canteiros foram adubados com $90 \mathrm{dm}^{3} \mathrm{ha}^{-1}$ de esterco bovino (equivalente, em matéria seca, a 23,4 $\mathrm{Mg} \mathrm{ha}^{-1}$ ), 1,5 $\mathrm{Mg} \mathrm{ha}^{-1}$ de calcário dolomítico e $1,5 \mathrm{Mg} \mathrm{ha}^{-1}$ da mistura de cinzas vegetais com termofosfato (1:1, base em peso). Adubações de cobertura foram realizadas, somente nas plantas de alface, pela aplicação de 43,6 g de cama de aviário por planta. O esterco bovino revelou os seguintes resultados de análise (Embrapa, 1997): N, 18,6 g kg-1; P, 1,5 g kg-1; $\mathrm{K}, 6,4 \mathrm{~g} \mathrm{~kg}^{-1}$; Ca, $6,1 \mathrm{~g} \mathrm{~kg}^{-1}$ e $\mathrm{Mg}, 1,4 \mathrm{~g} \mathrm{~kg}^{-1}$, enquanto a cama de aviário apresentou: $\mathrm{N}, 33,9 \mathrm{~g} \mathrm{~kg}^{-1}$; P, 13,6 g kg-1; K, 19,3 g kg-1$^{-1}$ Ca, 25,5 g kg-1 e $\mathrm{Mg}, 4,3 \mathrm{~g} \mathrm{~kg}^{-1}$. O calcário utilizado continha teores de $\mathrm{CaO}$ e $\mathrm{MgO}$, respectivamente, de 330 e $130 \mathrm{~g} \mathrm{~kg}^{-1}$. $\mathrm{O}$ termofostato magnesiano forneceu $79 \mathrm{~g}$ de P, $90 \mathrm{~g}$ de $\mathrm{Mg}$ e $200 \mathrm{~g}$ de Ca por quilograma do produto comercial. Por sua vez, as cinzas vegetais apresentaram a seguinte composição: $\mathrm{P}, 8,3 \mathrm{~g} \mathrm{~kg}^{-1}$; K, 40,3 $\mathrm{g} \mathrm{kg}^{-1}$; Ca, 16,9 $\mathrm{g} \mathrm{kg}^{-1}$; Mg, 2,8 g kg-1.

No período entre cada ano de cultivo, efetuou-se o plantio de mucuna-cinza (Mucuna pruriens) como proteção do solo e adubação verde. No segundo ano depois do corte e da incorporação da biomassa de mucuna, os canteiros foram refeitos. A adubação foi igual à do primeiro ano, omitida apenas a aplicação do calcário. As irrigações foram procedidas por aspersão, e os turnos de rega regulados de acordo com a espécie mais exigente, ou seja, a alface. 
O delineamento experimental, no primeiro experimento, foi o de blocos ao acaso, com quatro repetições. Os tratamentos consistiram de alface crespa (cultivar Verônica) em consórcio com cenoura (cultivar Brasília), alface crespa em consórcio com rabanete (Híbrido ㄲo19) e os cultivos solteiros de alface crespa, cenoura e rabanete. A parcela experimental foi constituída por uma área de 5,0x1,0 m. Nos cultivos solteiros, os espaçamentos empregados foram de $0,25 \times 0,25 \mathrm{~m}$ em alface; $0,25 \times 0,10 \mathrm{~m}$ em cenoura; e 0,15x0,05 m em rabanete. No consórcio entre alface e cenoura, manteve-se a cenoura no espaçamento do cultivo solteiro, sendo as mudas de alface plantadas nas entrelinhas da cenoura, em linhas alternadas, no sentido da largura dos canteiros. Já no consórcio entre alface e rabanete, manteve-se a alface no espaçamento do cultivo solteiro, sendo o rabanete semeado nas entrelinhas da alface, de igual forma, em linhas alternadas no sentido da largura dos canteiros.

No segundo experimento, os tratamentos consistiram de alface lisa (cultivar Regina 71) em consórcio com cenoura (cultivar Brasília); alface lisa em consórcio com rabanete (Híbrido no19); e os cultivos solteiros de alface lisa, cenoura e rabanete, também no delineamento de blocos ao acaso com quatro repetições. As dimensões das parcelas, assim como os espaçamentos e os arranjos entre as espécies foram os mesmos descritos para o primeiro experimento.

As mudas de alface foram produzidas na casa de vegetação, em bandejas de isopor com 128 células contendo substrato constituído de subsolo argiloso, areia lavada, esterco bovino curtido, cama de aviário e vermicomposto, na proporção de 4:2:2:1:1 (base em volume), ao qual foi adicionado de $5 \mathrm{~g} \mathrm{~kg}^{-1}$ da mistura de termofosfato com cinzas vegetais (1:1, base em peso). Três semanas depois da semeadura, as mudas de alface foram transplantadas para o campo. As semeaduras de cenoura e rabanete foram realizadas no mesmo dia do transplantio das mudas de alface.

A alface foi colhida 54 dias após o transplantio (dat), no primeiro ano experimental, e 46 dat (cv. Verônica) e 50 dat (cv. Regina 71), no segundo ano. A cenoura foi colhida aos 117 e 106 dias após a semeadura (das), respectivamente, no primeiro ano e no segundo ano. O rabanete foi colhido somente no segundo ano, aos 30 dias após semeadura.

Foram computados, na alface, o peso e o diâmetro da parte aérea (cabeça). Depois de lavadas e secadas, foram avaliados, nas cenouras, o peso, o comprimento e o diâmetro das raízes, enquanto no rabanete determinou-se somente o peso e o diâmetro das raízes.

Com base nos parâmetros de produtividade (produção comercial) das diferentes culturas, em cada ano de experimentação, calculou-se o uso eficiente da terra, por meio da expressão:

UET $=\left(\mathrm{C}_{\text {cultura } \mathrm{A}} / \mathrm{M}_{\text {cultura A }}\right)+\left(\mathrm{C}_{\text {cultura B }} / \mathrm{M}_{\text {cultura B }}\right)$, em que $\mathrm{C}$ e $\mathrm{M}$ representam, respectivamente, as produtividades do consórcio e do cultivo solteiro, referentes às espécies $\mathrm{A}$ e $\mathrm{B}$.

Por ocasião das colheitas, foram amostradas seis plantas de cada espécie por parcela, para determinação dos teores de nutrientes. Em relação à alface, coletouse a parte aérea, ao passo que, quanto à cenoura e ao rabanete, foram coletadas as raízes. Essas amostras foram secadas em estufa, com circulação forçada de ar, regulada em $65^{\circ} \mathrm{C}$, até massa constante. Em seguida, as amostras foram moídas, determinando-se, subseqüentemente, os teores $\mathrm{N}, \mathrm{P}, \mathrm{K}, \mathrm{Ca}$ e $\mathrm{Mg}$. O teor de $\mathrm{N}$ foi determinado pelo método Kjeldahl, e os dos demais elementos, por digestão nitroperclórica (Bataglia et al., 1983).

Foram calculadas as quantidades de nutrientes extraídas do solo pelas espécies em cada tratamento. Com base nos valores de entrada (via adubações) e saída (via colheita), calculou-se o balanço de macronutrientes relativo a cada sistema de condução das culturas (consórcio e cultivo solteiro).

Diferenças significativas entre os tratamentos foram comprovadas pela análise da variância, utilizando-se o teste F. Nos casos de constatação de diferença significativa, aplicou-se o teste de Tukey, a 5\% de probabilidade, para comparação entre médias.

\section{Resultados e Discussão}

Nos consórcios de alface 'Verônica' e 'Regina 71' com cenoura 'Brasília', independentemente do sistema de produção - cultivo solteiro ou consórcio -, obteve-se alto padrão comercial com o manejo orgânico (Tabela 1). Efeitos estimuladores, quanto a peso e diâmetro da parte aérea, foram observados em ambas as cultivares de alface consorciadas com cenoura, no segundo ano de experimentação. Tais efeitos podem ser atribuídos ao maior volume de solo disponível para absorção de água e nutrientes pela alface, devido à menor densidade de plantio, também sinalizando ausência de competição com a cenoura consorciada. 
Detectou-se maior desenvolvimento das raízes de cenoura, quando cultivada em consórcio com alface, crespa ou lisa, no primeiro ano experimental (Tabela 1). Os valores médios de comprimento e diâmetro das raízes de cenoura são comparáveis aos obtidos por Souza \& Resende (2003), em três anos de cultivo experimental, sob manejo orgânico, utilizando a mesma cultivar.

Aumento do peso das raízes de rabanete, quando consorciado com alface, crespa ou lisa, foi também detectado no segundo ano experimental (Tabela 1). De forma análoga ao ocorrido com a alface em consórcio com cenoura, esse efeito possivelmente deveu-se à menor densidade de plantio do rabanete no arranjo espacial.

O consórcio entre alface e rabanete não foi avaliado no primeiro ano experimental, em virtude do reduzido desenvolvimento do rabanete. Provavelmente, este fato decorreu da imobilização de nutrientes, ditada pela incorporação do capim-cameroon, cultivado previamente na área, tendo em vista que os resíduos dessa espécie de gramínea apresentam alta relação $\mathrm{C} / \mathrm{N}$. O fato de o rabanete apresentar ciclo especialmente curto - em torno de 30 dias da semeadura à colheita -, portanto necessitando de nutrientes prontamente disponíveis, pode ter agravado os efeitos prejudiciais do processo de imobilização no solo.
Os valores relacionados à produtividade e ao uso eficiente da terra, no experimento de consórcio de alface 'Verônica' com cenoura ou rabanete, estão indicados na Tabela 2. A elevada produtividade da alface no cultivo solteiro (média de 54,8 $\mathrm{Mg} \mathrm{ha}^{-1}$ ) superou a encontrada por Andrade Junior et al. (1992) para a mesma cultivar. Da mesma forma, foram encontrados altos valores de produtividade da cenoura, tanto no cultivo solteiro como em consórcio com alface. A produtividade em raízes comerciais, considerando os dois sistemas de plantio, foi de $41 \mathrm{Mg} \mathrm{ha}^{-1}$, superior aos valores reportados por Ribeiro et al. (1993). Por sua vez, a produtividade média do rabanete, em cultivo solteiro, foi de $31,5 \mathrm{Mg} \mathrm{ha}^{-1}$, mostrando-se comparável às estimativas para o sistema convencional de condução da cultura (Filgueira, 2000). O uso eficiente da terra no consórcio entre alface 'Verônica' e cenoura situou-se acima da unidade, indicando grau de eficiência de $70 \%$, no primeiro, e de $62 \%$, no segundo ano de experimentação. Quanto ao consórcio com o rabanete, observou-se eficiência quanto ao uso da terra de $54 \%$.

Resultados igualmente promissores quanto à produtividade e uso eficiente da terra foram obtidos com o consórcio entre alface 'Regina 71' e cenoura ou rabanete (Tabela 2). A produtividade da alface, em cultivo

Tabela 1. Peso, diâmetro e comprimento das raízes de cenoura 'Brasília' e peso e diâmetro da parte aérea de alface crespa 'Verônica' ou alface lisa 'Regina 71' e das raízes de rabanete 'Híbrido noํ 19', sob manejo orgânico, em cultivos solteiro ou consorciado nos anos de 1996 e $1997^{(1)}$.

\begin{tabular}{|c|c|c|c|c|c|c|}
\hline \multirow[t]{2}{*}{ Sistemas de cultivo } & \multicolumn{2}{|c|}{$\begin{array}{c}\text { Peso } \\
\left(\text { g planta }^{-1}\right)\end{array}$} & \multicolumn{2}{|c|}{$\begin{array}{c}\text { Diâmetro } \\
(\mathrm{cm})\end{array}$} & \multicolumn{2}{|c|}{$\begin{array}{l}\text { Comprimento } \\
(\mathrm{cm})\end{array}$} \\
\hline & $1^{\underline{0}}$ ano & $2^{-}$ano & $1^{\underline{o}}$ ano & $2^{\underline{0}}$ ano & $1^{\circ}$ ano & $2^{\underline{Q}}$ ano \\
\hline & \multicolumn{6}{|c|}{$\begin{array}{c}\text { Consórcios envolvendo alface crespa } \\
\text { Parte aérea de alface }\end{array}$} \\
\hline Alface crespa (cultivo solteiro) & $343,2 \mathrm{a}$ & $342,7 \mathrm{~b}$ & $35,2 \mathrm{a}$ & $38,8 \mathrm{~b}$ & - & - \\
\hline Alface crespa (consórcio com cenoura) & $334,2 a$ & $423,2 a$ & $33,1 \mathrm{a}$ & $43,7 \mathrm{a}$ & - & - \\
\hline \multirow[t]{2}{*}{ Alface crespa (consórcio com rabanete) } & - & $331,7 \mathrm{~b}$ & - & $38,4 \mathrm{~b}$ & - & - \\
\hline & \multicolumn{6}{|c|}{ Raiz de cenoura } \\
\hline Cenoura (cultivo solteiro) & $58,8 \mathrm{~b}$ & $117,3 \mathrm{a}$ & $2,81 b$ & $3,18 \mathrm{a}$ & $11,4 \mathrm{a}$ & $15,6 \mathrm{a}$ \\
\hline \multirow[t]{2}{*}{ Cenoura (consórcio com alface crespa) } & $79,3 \mathrm{a}$ & $117,3 \mathrm{a}$ & $3,09 \mathrm{a}$ & $3,21 \mathrm{a}$ & $12,6 \mathrm{a}$ & $14,8 \mathrm{a}$ \\
\hline & \multicolumn{6}{|c|}{ Raiz de rabanete } \\
\hline Rabanete (cultivo solteiro) & - & $25,6 b$ & - & $3,61 \mathrm{a}$ & - & - \\
\hline \multirow[t]{2}{*}{ Rabanete (consórcio com alface crespa) } & - & $37,3 a$ & - & $3,94 \mathrm{a}$ & - & - \\
\hline & \multicolumn{6}{|c|}{$\begin{array}{c}\text { Consórcios envolvendo alface lisa } \\
\text { Parte aérea de alface }\end{array}$} \\
\hline Alface lisa (cultivo solteiro) & $284,2 \mathrm{a}$ & $343,9 \mathrm{ab}$ & $30,7 \mathrm{a}$ & $35,0 \mathrm{a}$ & - & - \\
\hline Alface lisa (consórcio com cenoura) & $335,3 \mathrm{a}$ & $384,8 \mathrm{a}$ & $33,1 \mathrm{a}$ & $35,5 \mathrm{a}$ & - & - \\
\hline \multirow[t]{2}{*}{ Alface lisa (consórcio com rabanete) } & - & $274,7 \mathrm{~b}$ & - & $33,8 \mathrm{a}$ & - & - \\
\hline & \multicolumn{6}{|c|}{ Raiz de cenoura } \\
\hline Cenoura (cultivo solteiro) & $44,5 b$ & $112,1 \mathrm{a}$ & $2,40 \mathrm{~b}$ & $3,19 \mathrm{a}$ & $11,1 \mathrm{a}$ & $15,1 \mathrm{a}$ \\
\hline \multirow[t]{2}{*}{ Cenoura (consórcio com alface lisa) } & $75,3 \mathrm{a}$ & $114,4 \mathrm{a}$ & $2,94 \mathrm{a}$ & $3,27 \mathrm{a}$ & $12,7 \mathrm{a}$ & $14,8 \mathrm{a}$ \\
\hline & \multicolumn{6}{|c|}{ Raiz de rabanete } \\
\hline Rabanete (cultivo solteiro) & - & $35,2 b$ & - & $4,00 \mathrm{a}$ & - & - \\
\hline Rabanete (consórcio com alface lisa) & - & $43,8 \mathrm{a}$ & - & $4,28 \mathrm{a}$ & - & - \\
\hline
\end{tabular}

(1)Médias seguidas pela mesma letra não diferem entre si pelo teste de Tukey, a 5\% de probabilidade. 
solteiro, foi de $50 \mathrm{Mg} \mathrm{ha}^{-1}$, suplantando a faixa de 20-30 Mg ha ${ }^{-1}$ relatada por Filgueira (2000) para este grupo de alface no Brasil. Caetano et al. (1999) conseguiram produtividade de $58 \mathrm{Mg} \mathrm{ha}^{-1}$ com a cv. Regina 71 em cultivo solteiro e de $52 \mathrm{Mg} \mathrm{ha}^{-1}$ quando consorciada com cenoura 'Brasília', em ensaio conduzido na Região Norte Fluminense.

Produtividades relativas à cenoura e ao rabanete consorciados com alface 'Regina 71' foram similares às do primeiro experimento. Quanto ao consórcio entre alface 'Regina 71' e cenoura, houve eficiência no uso da terra de $80 \%$, no primeiro ano, e de $47 \%$, no segundo ano. Valores inferiores de UET foram relatados por Negreiros et al. (2002), que avaliaram consórcios entre diferentes cultivares de alface e cenoura 'Brasília' em Mossoró, RN. Quanto ao consórcio entre alface 'Regina 71' e rabanete, observou-se aproveitamento de área $27 \%$ superior ao obtido com os respectivos cultivos solteiros. De acordo com Sudo et al. (2001), a inclusão do rabanete nesse tipo de consórcio com alface, nas condições edafoclimáticas da Baixada Fluminense, representa um ganho adicional para o agricultor, além

Tabela 2. Produtividade de alface crespa 'Verônica' ou alface lisa 'Regina 71', cenoura 'Brasília' e rabanete 'Híbrido no 19', sob manejo orgânico, em cultivos solteiro ou consorciado, com os respectivos índices de uso eficiente da terra nos anos de 1996 e 1997.

\begin{tabular}{|c|c|c|}
\hline \multirow[t]{2}{*}{ Sistemas de cultivo } & \multicolumn{2}{|c|}{ Produtividade $\left(\mathrm{Mg} \mathrm{ha}^{-1}\right)$} \\
\hline & $1^{\circ}$ ano $(1996)$ & $2^{\underline{0}}$ ano (1997) \\
\hline & \multicolumn{2}{|c|}{ Consórcio alface crespa-cenoura } \\
\hline Alface crespa (cultivo solteiro) & 54,9 & 54,8 \\
\hline Alface crespa (consórcio com cenoura) ${ }^{(1)}$ & 26,7 & 33,8 \\
\hline Cenoura (cultivo solteiro) & 35,9 & 42,1 \\
\hline Cenoura (consórcio com alface crespa) & 43,5 & 42,3 \\
\hline \multirow[t]{2}{*}{ Uso Eficiente da Terra (UET) } & 1,70 & 1,62 \\
\hline & \multicolumn{2}{|c|}{ Consórcio alface crespa-rabanete } \\
\hline Alface crespa (cultivo solteiro) & - & 54,8 \\
\hline Alface crespa (consórcio com rabanete) & - & 53,1 \\
\hline Rabanete (cultivo solteiro) & - & 31,5 \\
\hline Rabanete (consórcio com alface crespa) ${ }^{(2)}$ & - & 18,1 \\
\hline \multirow{2}{*}{ Uso Eficiente da Terra (UET) } & - & 1,54 \\
\hline & \multicolumn{2}{|c|}{ Consórcio alface lisa-cenoura } \\
\hline Alface lisa (cultivo solteiro) & 45,5 & 55,0 \\
\hline Alface lisa (consórcio com cenoura) ${ }^{(1)}$ & 26,8 & 30,8 \\
\hline Cenoura (cultivo solteiro) & 36,8 & 45,9 \\
\hline Cenoura (consórcio com alface lisa) & 44,5 & 42,0 \\
\hline \multirow[t]{2}{*}{ Uso Eficiente da Terra (UET) } & 1,80 & 1,47 \\
\hline & \multicolumn{2}{|c|}{ Consórcio alface lisa-rabanete } \\
\hline Alface lisa (cultivo solteiro) & - & 55,0 \\
\hline Alface lisa (consórcio com rabanete) & - & 43,9 \\
\hline Rabanete (cultivo solteiro) & - & 46,9 \\
\hline Rabanete (consórcio com alface lisa) ${ }^{(2)}$ & - & 22,0 \\
\hline Uso Eficiente da Terra (UET) & - & 1,27 \\
\hline
\end{tabular}

de contribuir com a redução dos custos de produção, sem reduzir significativamente a produção da alface.

As quantidades de nutrientes extraídas do sistema, por meio das colheitas dos cultivos solteiros de alface (crespa e lisa), cenoura e rabanete, assim como dos respectivos consórcios, são apresentadas na Tabela 3. O consórcio entre alface, (independentemente da cultivar) e cenoura resultou em valores mais elevados de N, $\mathrm{P}$ e $\mathrm{K}$ extraídos, em comparação aos respectivos cultivos solteiros durante o primeiro ano experimental, ao passo que, no segundo ano, não foram constatadas diferenças quanto à quantidade de nutrientes extraídas nesses sistemas de cultivo. Valores de extração de nutrientes obtidos nos consórcios entre quaisquer das duas cultivares de alface e o rabanete foram similares aos do cultivo solteiro de rabanete, mas superiores em relação aos de alface.

Com base nesses resultados, comprova-se maior aproveitamento de nutrientes disponíveis pelos cultivos consorciados, levando-se em conta que receberam a mesma adubação dos respectivos cultivos solteiros. De forma semelhante, Oliveira et al. (2005) estudaram

Tabela 3. Quantidades de macronutrientes extraídas com as colheitas de alface crespa 'Verônica' ou alface lisa 'Regina 71', cenoura 'Brasília' e rabanete 'Híbrido no 19', sob manejo orgânico, em cultivos solteiro ou consorciado nos anos de 1996 e $1997^{(1)}$.

\begin{tabular}{|c|c|c|c|c|c|}
\hline \multirow[t]{2}{*}{ Sistemas de cultivo } & $\mathrm{N}$ & $\mathrm{P}$ & K & $\mathrm{Ca}$ & $\mathrm{Mg}$ \\
\hline & & & $\left(\mathrm{kg} \mathrm{ha}^{-1}\right)$ & & - \\
\hline & \multicolumn{5}{|c|}{$\begin{array}{c}\text { Consórcios envolvendo alface crespa } \\
1^{\circ} \text { ano (1996) }\end{array}$} \\
\hline Alface crespa (cultivo solteiro) & $80,6 \mathrm{~b}$ & $17,0 \mathrm{c}$ & $188,5 \mathrm{~b}$ & $19,2 \mathrm{~b}$ & $7,5 b$ \\
\hline Cenoura (cultivo solteiro) & $71,5 \mathrm{~b}$ & $36,3 b$ & $273,8 b$ & $124,7 \mathrm{a}$ & $27,3 \mathrm{a}$ \\
\hline \multirow[t]{2}{*}{ Consórcio alface crespa-cenoura ${ }^{(2)}$} & $122,7 \mathrm{a}$ & $51,2 \mathrm{a}$ & $393,9 \mathrm{a}$ & $100,6 \mathrm{a}$ & $27,4 \mathrm{a}$ \\
\hline & \multicolumn{5}{|c|}{$2^{\underline{0}}$ ano $(1997)$} \\
\hline Alface crespa (cultivo solteiro) & $77,0 \mathrm{~b}$ & $17,3 \mathrm{c}$ & $98,0 \mathrm{c}$ & $20,1 \mathrm{c}$ & $5,7 \mathrm{c}$ \\
\hline Cenoura (cultivo solteiro) & $88,3 \mathrm{~b}$ & $23,9 b c$ & $165,1 b c$ & $51,8 \mathrm{~b}$ & $15,3 b c$ \\
\hline Rabanete (cultivo solteiro) & $213,8 \mathrm{a}$ & $34,4 a b$ & $293,9 a$ & $107,5 \mathrm{a}$ & $33,6 \mathrm{a}$ \\
\hline \multirow[t]{2}{*}{ Consórcio alface crespa-cenoura } & $165,2 \mathrm{ab}$ & $40,6 \mathrm{a}$ & $247,4 \mathrm{ab}$ & $68,7 \mathrm{~b}$ & $20,6 b$ \\
\hline & \multicolumn{5}{|c|}{$\begin{array}{c}\text { Consórcios envolvendo alface lisa } \\
1^{\circ} \text { ano (1996) }\end{array}$} \\
\hline Alface lisa (cultivo solteiro) & $67,9 \mathrm{~b}$ & $13,3 \mathrm{c}$ & $129,8 \mathrm{~b}$ & $12,5 b$ & $6,2 \mathrm{c}$ \\
\hline Cenoura (cultivo solteiro) & $48,2 \mathrm{c}$ & $27,0 \mathrm{~b}$ & $178,4 \mathrm{~b}$ & $65,2 \mathrm{a}$ & $15,0 \mathrm{~b}$ \\
\hline \multirow[t]{2}{*}{ Consórcio alface lisa-cenoura ${ }^{(2)}$} & $116,2 \mathrm{a}$ & $49,6 \mathrm{a}$ & $356,1 \mathrm{a}$ & $87,3 \mathrm{a}$ & $25,8 \mathrm{a}$ \\
\hline & \multicolumn{5}{|c|}{$2^{\underline{0}}$ ano (1997) } \\
\hline Alface lisa (cultivo solteiro) & $72,9 \mathrm{c}$ & $17,6 \mathrm{~b}$ & $83,0 \mathrm{~b}$ & $18,2 \mathrm{c}$ & $6,5 \mathrm{c}$ \\
\hline Cenoura (cultivo solteiro) & $94,2 \mathrm{c}$ & $27,7 \mathrm{ab}$ & $180,3 \mathrm{ab}$ & $49,4 b$ & $16,0 \mathrm{~b}$ \\
\hline Rabanete (cultivo solteiro) & $247,8 \mathrm{a}$ & $34,5 \mathrm{a}$ & $262,7 \mathrm{a}$ & $95,4 \mathrm{a}$ & $30,7 \mathrm{a}$ \\
\hline Consórcio alface lisa-cenoura & $119,9 \mathrm{bc}$ & $34,8 \mathrm{a}$ & $280,9 a$ & $58,9 \mathrm{~b}$ & $19,8 \mathrm{~b}$ \\
\hline Consórcio alface lisa-rabanete ${ }^{(3)}$ & $164,5 \mathrm{~b}$ & $28,4 \mathrm{ab}$ & $189,9 \mathrm{ab}$ & $55,3 \mathrm{~b}$ & $19,6 \mathrm{~b}$ \\
\hline
\end{tabular}

Pesq. agropec. bras., Brasília, v.41, n.7, p.1141-1147, jul. 2006 
o consórcio entre repolho e rabanete, sob manejo orgânico, indicando que essa prática favorece maior recuperação de nutrientes por unidade de área, em relação aos respectivos monocultivos.

Por meio da observação da relação entre a entrada (via adubações) e a saída (via colheitas), foi possível calcular o balanço de nutrientes em cada sistema de cultivo avaliado. $\mathrm{O} \mathrm{K}$ foi o único nutriente com valores médios negativos, nos dois experimentos, para cenoura em cultivo solteiro (-77,78 $\left.\mathrm{kg} \mathrm{ha}^{-1}\right)$, rabanete em cultivo solteiro (-98,35 kg ha-1), consórcio entre alface 'Verônica' e cenoura (-39,63 $\left.\mathrm{kg} \mathrm{ha}^{-1}\right)$ e consórcio entre alface 'Regina 71' e cenoura (-37,41 $\left.\mathrm{kg} \mathrm{ha}^{-1}\right)$. Esses valores negativos indicam que o $\mathrm{K}$ fornecido como adubo foi exportado, o que, provavelmente, resultou em redução dos teores de $\mathrm{K}$ do solo. Tais resultados mostram-se coerentes com os obtidos por Salgado et al. (1998), em estudo conduzido no mesmo local, sobre balanços de nutrientes em várias culturas no sistema orgânico de produção. Oliveira (2001) também chama a atenção para o balanço de nutrientes de rabanete em cultivo solteiro, o qual extraiu quantidades de nutrientes maiores que o aporte proporcionado pela adubação. Segundo esse autor, o deficit formado em tal situação pode exaurir a fertilidade do solo, tornando necessário um ajuste no aporte de nutrientes, de modo a repor as quantidades extraídas.

De acordo com os dados referentes aos consórcios alface-cenoura e alface-rabanete - independentemente da cultivar de alface incluída, esses sistemas são vantajosos. Sua adoção possibilita colheita e renda adicionais, além de otimizar práticas culturais e de favorecer o aproveitamento de nutrientes disponíveis no solo.

\section{Conclusões}

1. Os consórcios de cultivares de alface ('Regina 71' e 'Verônica') com cenoura 'Brasília' ou com rabanete 'Híbrido no 19' apresentam elevados valores de uso eficiente da terra.

2. Há maior eficiência quanto ao aproveitamento de macronutrientes disponíveis no solo, com exceção do potássio, nos consórcios avaliados, em comparação com o cultivo solteiro, nas condições edafoclimáticas da Baixada Fluminense.

\section{Referências}

ALMEIDA, D.L. de; GUERRA, J.G.M.; RIBEIRO, R. de L.D. Sistema Integrado de Produção Agroecológica: uma experiência de pesquisa em agricultura orgânica. Seropédica: Embrapa Agrobiologia, 2003. 37p. (Documentos, 169).

ALTIERI, M. Agroecologia: bases científicas para uma agricultura sustentável. Guaíba: Agropecuária, 2002. 592p.

ANDRADE JUNIOR, A.S. de; DUARTE, R.L.R.; RIBEIRO, V.Q. Resposta de cultivares de alface a diferentes níveis de irrigação. Horticultura Brasileira, v.10, p.95-97, 1992.

BARROS JÚNIOR, A.P.; BEZERRA NETO, F.; NEGREIROS, M.Z. de; OLIVEIRA, E.Q. de; SILVEIRA, L.M. da; CÂMARA, M.J.T. Desempenho agronômico do bicultivo da alface em sistemas consorciados com cenoura em faixa sob diferentes densidades populacionais. Horticultura Brasileira, v.23, p.712-717, 2005.

BATAGLIA, O.C.; FURLANI, A.M.C.; TEIXEIRA, J.P.F.; FURLANI, P.R.; GALLO, J.R. Métodos de análise química de plantas. Campinas: Instituto Agronômico de Campinas, 1983. 48p. (Boletim técnico, 78).

BAUMANN, D.T.; BASTIAANS, L.; KROPFF, M.J. Competition and crop performance in a leek-celery intercropping system. Crop Science, v.41, p.764-774, 2001.

CAETANO, L.C.S.; FERREIRA, J.M.; ARAÚJO, M.L. Produtividade de cenoura e alface em sistema de consorciação. Horticultura Brasileira, v.17, p.143-146, 1999.

EMBRAPA. Centro Nacional de Pesquisa de Solos (Rio de Janeiro, RJ). Manual de métodos de análise de solo. Rio de Janeiro, 1997. 212p.

FAGERIA, N.K. Sistemas de cultivo consorciado. In: FAGERIA, N.K. (Ed.). Solos tropicais e aspectos fisiológicos das culturas. Brasília: Embrapa-DPU, 1989. p.185-196.

FILGUEIRA, F.A.R. Novo manual de olericultura: agrotecnologia moderna na produção e comercialização de hortaliças. Viçosa: UFV, 2000. 402p.

GLIESSMAN, S.R. Agroecologia: processos ecológicos em agricultura sustentável. 2.ed. Porto Alegre: Ed. da Universidade, 2001. 653p.

HOOKS, C.R.R.; JOHNSON, M.W. Impact of agricultural diversification on the insect community of cruciferous crops. Crop Protection, v.22, p.223-238, 2003.

HUMPHRIES, A.W.; LATTA, R.A.; AURICHT, G.C.; BELLOTTI, W.D. Over-cropping lucerne with wheat: effect of lucerne winter activity on total plant production and water use of the mixture, and wheat yield and quality. Australian Journal of Agricultural Research, v.55, p.839-848, 2004.

IIJIMA, M.; IZUMI, Y.; YULIADI, E.; SUNYOTO; ARDJASA, W.S. Cassava-based intercropping systems on Sumatra Island in Indonesia: productivity, soil erosion, and rooting zone. Plant Production Science, v.7, p.347-355, 2004.

NEGREIROS, M.Z. de; BEZERRA NETO, F.; PORTO, V.C.N.; SANTOS, R.H.S. Cultivares de alface em sistemas solteiro e consorciado com cenoura em Mossoró. Horticultura Brasileira, v.20, p.162-166, 2002.

OLIVEIRA, F.L. de. Manejo orgânico da cultura do repolho (Brassica oleracea var. capitata): adubação orgânica, adubação verde e consorciação. 2001. 87p. Dissertação (Mestrado) - Universidade Federal Rural do Rio de Janeiro, Seropédica. 
OLIVEIRA, F.L. de; RIBAS, R.G.T.; JUNQUEIRA, R.M.; PADOVAN, M.P.; GUERRA, J.G.M.; ALMEIDA, D.L. de; RIBEIRO, R. de L.D. Desempenho do consórcio entre repolho e rabanete com pré-cultivo de crotalária, sob manejo orgânico. Horticultura Brasileira, v.23, p.184-188, 2005.

RIBEIRO, L.G.; PEIXOTO, C.L.H.; AMIGO, F. Avaliação de cultivares de cenoura em Alegre, ES. Horticultura Brasileira, v.11, p.52-53, 1993.

SALGADO, J.A. de A.; ALMEIDA, D.L. de; GUERRA, J.G.M.; RIBEIRO, R. de L.D.; SUDO, A. Balanço de nutrientes em cultivos de hortaliças sob manejo orgânico. Seropédica: Embrapa-CNPAB, 1998. 9p. (Comunicado técnico, 21).
SOUZA, J.L. de; RESENDE, P. Manual de agricultura orgânica. Viçosa: Aprenda Fácil, 2003. 564p.

SUDO, A.; OLIVEIRA, F.L. de; GUERRA, J.G.M.; ALMEIDA, D.L. de; RIBEIRO, R. de L.D. Cultivo consorciado de alface e rabanete sob manejo orgânico. Seropédica: Embrapa Agrobiologia, 2001. 4p. (Recomendação técnica, 10).

VANDERMEER, J.H. Intercropping. In: GLIESSMAN, S.R. (Ed.). Agroecology: researching the ecological basis for sustainable agriculture. New York: Springer-Verlag, 1990. p.481-516.

ZHANG, F.; SHEN, J.; LI, L.; LIU, X. An overview of rhizosphere processes related with plant nutrition in major cropping systems in China. Plant and Soil, v.260, p.89-99, 2004.

Recebido em 22 de agosto de 2005 e aprovado em 13 de março de 2006 